\title{
Protamine 3 '-untranslated sequences regulate temporal translational control and subcellular localization of growth hormone in spermatids of transgenic mice
}

\author{
Robert E. Braun, Jacques J. Peschon, Richard R. Behringer, ${ }^{1}$ Ralph L. Brinster, ${ }^{1}$ \\ and Richard D. Palmiter \\ Howard Hughes Medical Institute and Department of Biochemistry, University of Washington SL-15, Seattle, Washington \\ 98195 USA; ${ }^{1}$ Laboratory of Reproductive Physiology, School of Veterinary Medicine, University of Pennsylvania, \\ Philadelphia, Pennsylvania 19104 USA
}

\begin{abstract}
Although the mouse protamine 1 gene ( $\mathrm{mP1}$ ) is first transcribed in round spermatids, its $\mathrm{mRNA}$ is not translated until about 1 week later in elongating spermatids. To determine what mP1 sequences are important for its transcriptional and translational regulation, we have constructed fusions between mP1 and the human growth hormone (hGH) structural gene and analyzed their expression in transgenic mice. We show that mP1 sequences $5^{\prime}$ to the start of transcription are sufficient to confer spermatid-specific expression on the hGH gene. We also show that 156 nucleotides of $\mathrm{mP1} 3^{\prime}$-untranslated sequence is sufficient to confer mP1-like translational regulation on the hGH mRNA. Interestingly, the subcellular localization of hGH was dependent on the time during spermiogenesis that it was made. Synthesis of hGH in early round spermatids resulted in localization in the acrosome, whereas synthesis in late elongating spermatids resulted in intracellular, but not acrosomal, localization.
\end{abstract}

[Key Words: Protamine; translational regulation; acrosome; protein sorting]

Received February 28, 1989; revised version accepted April 4, 1989.

During the haploid stage of spermatogenesis, called spermiogenesis, round spermatids differentiate into spermatozoa (Bellve 1979; Hecht 1986). Among the many morphological changes that occur are the reshaping of the nucleus (Fawcett et al. 1971; Dooher and Bennett 1973), the development of a flagellum (Fawcett and Phillips 1969), and the construction of the acrosome (Fawcett et al. 1971), a secretory vesicle located on the apical surface of the nucleus that is required for egg penetration during fertilization (Wassarman 1987). In the mouse, spermiogenesis lasts $\sim 2$ weeks and has been described as consisting of 16 stages based on various morphological criteria associated with changes in nuclear morphology and acrosomal development (Oakberg 1956).

The mouse protamine 1 (mP1) gene is one of two genes that encodes small basic proteins that replace the histones and testis basic proteins during sperm nuclear condensation (Bellve 1979). Protamine 1 expression is under both transcriptional and translational control. The gene is transcribed exclusively in haploid round spermatids (Hecht et al. 1986). mP1 mRNA is stored as a cytoplasmic ribonucleoprotein particle $(\mathrm{mRNP})$ for up to 1 week before it is translated in elongating spermatids (Balhorn et al. 1984; Kleene et al. 1984).

Translational control is an important mechanism of regulation during spermatogenesis in many organisms. In the rainbow trout, protamine mRNA is stored for 15-30 days before it is translated (Iatrou and Dixon 1977). In Drosophila, where there is no postmeiotic transcription (Olivieri and Olivieri 1965), and in the mouse, where transcription ceases at about stage 9 (Monesi 1964; Kierszenbaum and Tres 1975), many proteins required for spermatozoon assembly are not synthesized until days after transcription ceases $\left(\mathrm{O}^{\prime} \mathrm{Brien}\right.$ and Bellve 1980; Kuhn et al. 1988). Synthesis of these proteins is therefore dependent on mRNAs made either during meiosis or in early spermiogenesis. However, not all mRNAs are subject to translational regulation. Translation of other mRNAs occurs in early round spermatids, implying that a selective mechanism exists that 'earmarks' specific mRNAs for storage. In addition to mRNA storage, there may also be a defined temporal program for the translational recruitment of specific mRNAs encoding different components of the various spermatozoon structures. The mechanisms of selective mRNA storage and activation are poorly understood. The abundance of the MPI mRNA in spermatids and the precision of its translational control make it an excellent system in which to begin investigating such mechanisms.

We have previously described the cloning of the mP1 
gene and studied its transcriptional regulation in transgenic mice (Peschon et al. 1987). Recently, we have shown that as little as $0.46 \mathrm{~kb}$ of $\mathrm{mPl} 5^{\prime}$ sequence is sufficient to direct the expression of an oligonucleotidetagged version of $\mathrm{mPl}$ to haploid spermatids (Peschon et al. 1989). In this study we have extended the analysis of the transcriptional control and have also investigated the cis-acting sequence elements required for the proper translational regulation of $\mathrm{mPl}$. Our results demonstrate that the $\mathrm{mP1} 3^{\prime}$-untranslated region (UTR) contains all of the elements required for proper translational control and that they function even when transferred to a heterologous mRNA. Unexpectedly, we also discovered that the time during spermiogenesis at which different transgenic mRNAs are translated affects the subcellular localization of the product of the transgene within the developing spermatid.

\section{Results}

Tissue- and stage-specific transcriptional control

To study the transcriptional and translational regulation of the $\mathrm{mPl}$ gene, two fusion genes were constructed between $\mathrm{mPl}$ and the hGH gene (Fig. 1). Construct mP1hGH-mP1 3' contains $4.1 \mathrm{~kb}$ of the $\mathrm{mPl}$ gene extending $5^{\prime}$ to the transcription start site, $91 \mathrm{bp}$ of $\mathrm{mPl} 5^{\prime}$-untranslated sequence, the hGH structural gene, and 156 bp of $\mathrm{mP1} 3^{\prime}$-untranslated sequence. Construct $\mathrm{mPl}$ hGH-hGH $3^{\prime}$ is identical to mPl-hGH-mP1 3', except

A.

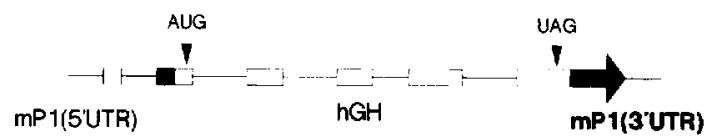

B.

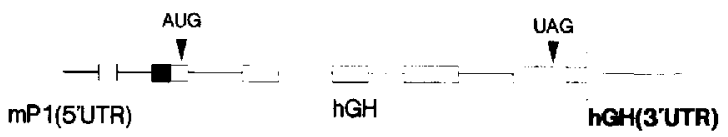

Figure 1. Transgene constructs. Nontranscribed and intron DNA are represented as thin lines, protamine exons (noncoding) are represented as solid boxes, and growth hormone exons are represented as open boxes. The positions of the translational start and stop codons are designated with arrows above the genes. The break in the line that corresponds to $\mathrm{mPl}$ sequence denotes that portion of the transgene that is not drawn to scale. Transgenes mPl-hGH-hGH $3^{\prime}$ and mPl-hGH-mPl $3^{\prime}$ both contain $\sim 4.1 \mathrm{~kb}$ of $\mathrm{mPl} 5^{\prime}$-untranscribed sequence extending $5^{\prime}$ from the transcriptional start site to a HindIII site at $-4.1 \mathrm{~kb}$. Both genes have chimeric 5' UTRs of $159 \mathrm{bp} \mid 91 \mathrm{bp}$ of mP1 5' UTR, 7 bp of linker DNA, and 61 bp of hGH 5' UTR) and the complete hGH-coding sequence and introns (DeNoto et al. 1981). mP1-hGH-hGH $3^{\prime}$ contains the complete wild-type hGH 3' UTR (105 bp), and transgene mP1-hGH-mP1 3' contains a chimeric $3^{\prime}$ UTR, which has the first 7 bp of the hGH $3^{\prime}$ UTR and $156 \mathrm{bp}$ of the mP1 3' UTR. that the MP1 3' UTR was replaced by the natural 112-bp hGH $3^{\prime}$ UTR. Transgenic mice were generated with each of the gene fusions by microinjection into the pronuclei of fertilized mouse eggs (Brinster et al. 1985).

Northern blot analysis of RNA isolated from the testes and six somatic tissues of animals carrying the two transgenes shows that expression of the transgenes was restricted to the testis (Fig. 2). The RNA blot was hybridized with a radiolabeled mP1 $5^{\prime}$ UTR probe that is complementary to the endogenous mP1 mRNA and to both transgene mRNAs. Figure 2 shows that the abundance of the two transgenic mRNAs and the endogenous $\mathrm{mP1}$ transcript were similar.

The first round of spermatogenesis in the mouse is synchronous, starts at birth, and is completed in $\sim 34$ days (Nebel et al. 1961). The time of appearance of an mRNA after birth can be used to deduce the cell type in which the gene is first expressed (Bellve 1979). Northern blot analysis shows that mRNA from both transgenes, as well as the endogenous $\mathrm{mPl}$ gene, was not detectable at day 19 after birth (Fig. 3, lanes a,f,k), a time at which cells at the leading edge of the first round of spermatogenesis are in the pachytene spermatocyte stage. However, at day 25 (lanes b,g, l), a time when cells in the first round are well into the haploid round spermatid stage, mRNA from both transgenes, as well as the endogenous gene, was detectable. The mRNAs continued to accumulate at day 28 and eventually reached a plateau in 32day-old and adult mice. These results suggest that both transgenes are transcribed exclusively in round spermatids and that $\mathrm{mPl} 5^{\prime}$ sequences extending from -4.1 $\mathrm{kb}$ to $+91 \mathrm{bp}$ are sufficient for appropriate $\mathrm{mP1}$ transcriptional control.

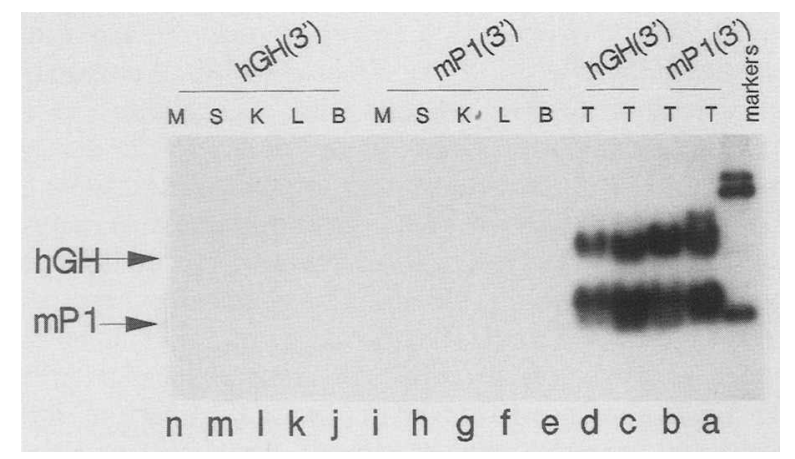

Figure 2. Tissue specificity Northern blot analysis. Total RNA (15 $\mu \mathrm{g}$ ) extracted from various tissues was separated on $1.5 \%$ agarose-formaldehyde gel, transferred to nitrocellulose paper, and hybridized with a ${ }^{32} \mathrm{P}$-labeled 175 -bp NcoI-NcoI fragment that contains $91 \mathrm{bp}$ of mP1 $5^{\prime}$ UTR, which both transgenes and the endogenous mP1 gene contain. Arrows designate the positions of the transgenic mRNAs and the endogenous mP1 mRNA. Letters above each lane represent the tissue from which the RNA was extracted: (T) testis; (B) brain; (L) liver; (K) kidney; (S) spleen; (M) skeletal muscle. (Lane b) RNA isolated from line 65-4 (mPl-hGH-mP1 3'); (lane d) RNA isolated from line 314-4 (mPl-hGH-hGH 3'); (lanes $a, e-i)$ RNA isolated from line 65-9 (mP1-hGH-mPl 3'); (lanes $c, j-n)$ RNA isolated from line 315-6 (mP1-hGH-hGH $3^{\prime}$ ). 


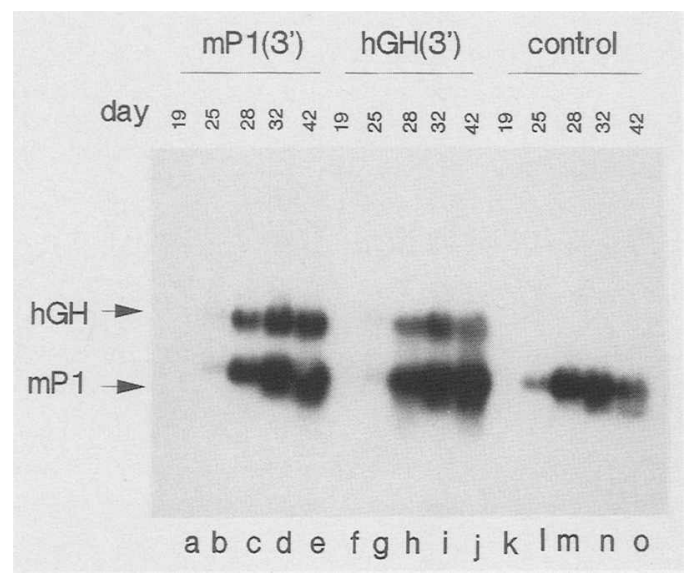

Figure 3. Prepubertal Northern blot analysis. RNA was isolated from the testes of animals 19, 25, 28,32, and 42 days old, and Northern blot analysis was performed as described in Fig. 2. (Lanes $a-e$ and $f-i)$ RNA isolated from lines 314-4 and 65-4, respectively; (lanes $k-o$ ) RNA isolated from nontransgenic littermates.

\section{Temporal translational regulation}

To determine the stage during prepubertal testis development at which the two transgenic mRNAs were translated, immunocytochemistry was performed on testis sections from prepubertal animals. In mice containing the mP1-hGH-mP1 $3^{\prime}$ construct (Fig. 4e), hGH was first detected in elongating spermatids within a small percentage of seminiferous tubules of 28-day-old animals. This corresponds to the same time that the endogenous $\mathrm{mPl}$ protein is also first detected (Balhom et al. 1984; Kleene et al. 1984). By day 32 (Fig. 4h), many of the tubules within the testis contained hGH immunopositive spermatids. Immunocytochemical analysis of adult testis showed that hGH was first detected in elongating spermatids at about stage 12 (Fig. $4 \mathrm{k}$ ). In contrast, in transgenic animals that contained the mP1-hGHhGH 3 ' gene, hGH protein was first detected in round spermatids in a few tubules at day 25 after birth (Fig. 4c). By day 28 (Fig. 4f), more tubules contained immunopositive spermatids, and by day 32 (Fig. 4i), many of the tubules were immunopositive. Immunocytochemical analysis of adult testes first revealed hGH in round spermatids at about stage $3-4$ (Fig. 41 ). This staging correlates with the most mature spermatids in day-22 prepubertal animals and is the earliest time at which $\mathrm{mPl}$ mRNA is detected (Kleene et al. 1983). Thus, despite the fact that the mP1-hGH-mP1 $3^{\prime}$ and mP1-hGH-hGH $3^{\prime}$ genes are under the same transcriptional control, translation of the two messages occurs at different stages of spermiogenesis. These results show that as little as

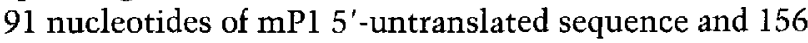
nucleotides of $\mathrm{mPl} 3$ '-untranslated sequence are sufficient to confer mPl-like translational control on a heterologous mRNA. In addition, these results demonstrate that the $\mathrm{mPl} 3^{\prime}$ UTR is necessary for proper translational control. We also tested a mP1-hGH-mPl $3^{\prime}$ con- struct that contained only $7 \mathrm{bp}$ of $\mathrm{mP1} 5^{\prime}$ UTR instead of 91 bp. Immunocytochemical analysis of testes from adult transgenic mice carrying this construct revealed that hGH was only synthesized in elongating spermatids, thus demonstrating that the MP1 3' UTR is sufficient for $\mathrm{mPl}$ translational control (data not shown).

\section{Subcellular localization of hGH protein}

Synthesis of hGH in early round spermatids versus late elongating spermatids resulted in different subcellular localization of the protein. In animals that contained the mPl-hGH-mPl $3^{\prime}$ gene, hGH protein accumulated intracellularly in elongating spermatids at about day 28 and continued to increase there through day 32 (Fig. 4). In animals that contained the mPl-hGH-hGH $3^{\prime}$ gene, $\mathrm{hGH}$ protein was localized in the acrosome of spermatids. At day 25 (Fig. 4c), and in adult animals (Fig. 4l), this can be seen as punctate staining adjacent to the nucleus; at day 28 (Fig. $4 \mathrm{ff}$ ), it is seen as a half-moon; and at day 32 \{Fig. 4i), it is seen as a crescent-shape stain corresponding to the shape of a mature acrosome. Thus, the time and, therefore, the stage at which hGH is synthesized during spermiogenesis determines its localization within the cell.

Immunocytochemistry of epididymal tissue from the mP1-hGH-mP1 3' animals also revealed the presence of hGH protein in the cytoplasm of the epithelial cells that line the efferent ducts (data not shown|. These cells are known to resorb fluids and cellular debris generated from the residual bodies and cytoplasmic droplets released by the spermatids (Mason and Shaver 1952), and it is likely that the hGH staining seen in them reflects their endocytic role. hGH was not seen in the epithelial cells of the efferent ducts in the mPl-hGH-hGH $3^{\prime}$ animals. This observation is consistent with immunocytochemical data that revealed that hGH was stable in the acrosome at least through the caput section of the epididymis (Braun et al. 1989).

To confirm the differential translational regulation of the two transgenes, total SDS-soluble protein extracts were prepared from the testes of transgenic animals aged $19,25,28$, and 32 days old and analyzed by Western blot analysis with hGH-specific antibodies (Fig. 5). hGH was first detected at day 28 (lane e) in those animals that contained the $\mathrm{mPl}$-hGH-hGH $3^{\prime}$ construct and at day 32 (lane $\mathrm{h}$ ) in those animals that contained the mP1-hGHmP1 3' construct. The time during prepubertal development that hGH was first detected was delayed for both constructs due to the lower sensitivity of this method compared to immunocytochemistry. Figure 5 shows that the amount of protein that eventually accumulated (lanes $g, h$ ) was approximately equivalent. These results confirm the immunocytochemical analysis showing that the two transgenes are under different translational control.

$\mathrm{hGH}$ is normally a secreted protein and is synthesized with an amino-terminal signal peptide that is cleaved in the rough endoplasmic reticulum (RER) to generate the mature secreted protein. Figure 5 shows that a protein of 
Braun et al.
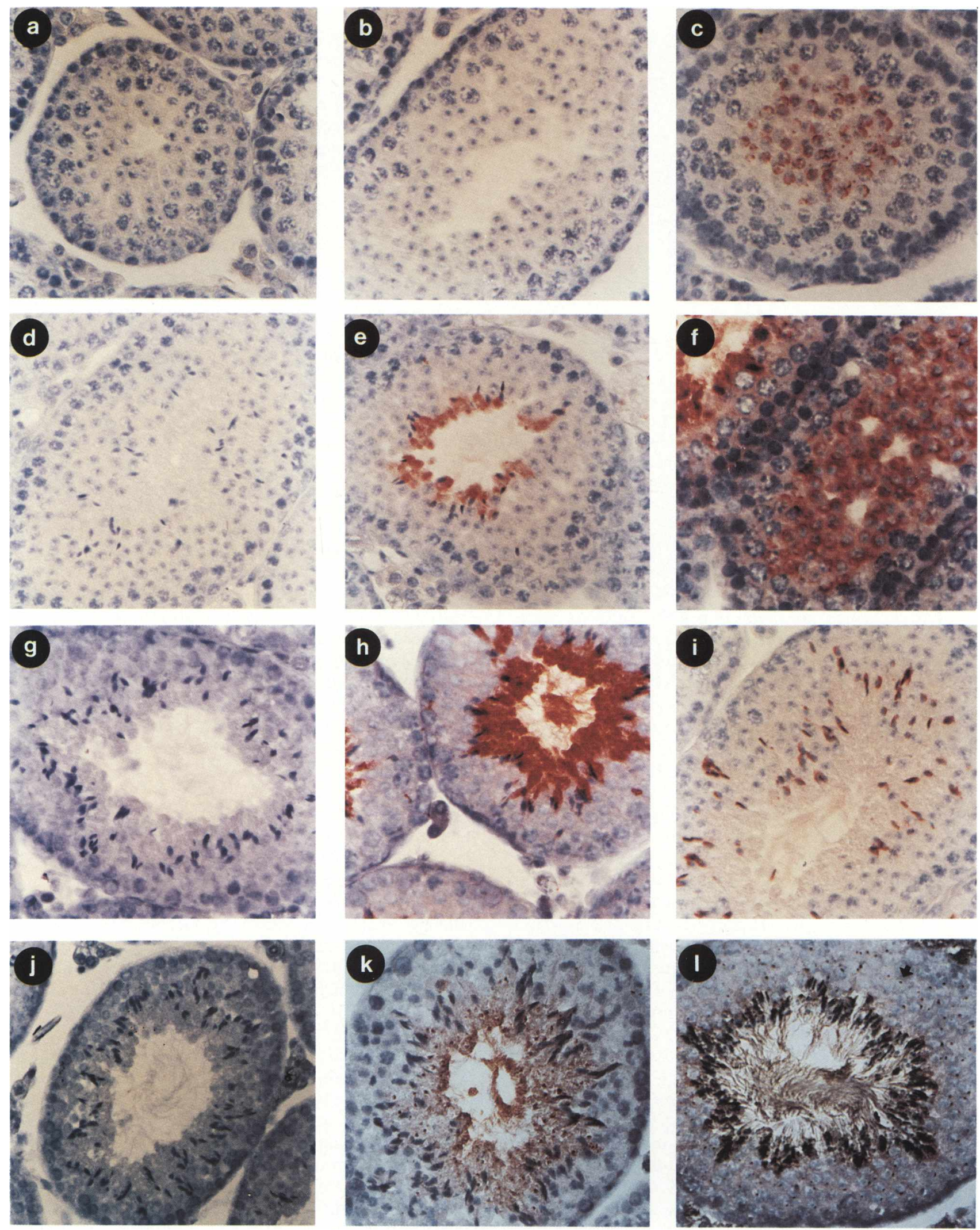

Figure 4. Prepubertal immunocytochemical analysis. Testes from prepubertal animals, aged $25(a-c), 28(d-f)$, or 32 days old $|g-i|$, and adult animals $(j-1)$ were fixed, sectioned, and treated with a rabbit anti-hGH primary antibody and a peroxidase-conjugated goat anti-rabbit secondary antibody, as described in Methods. $(a, d, g, j)$ Sections were from animals of the 65-4 line (mPl-hGH-mP1 $\left.3^{\prime}\right)$ and were only incubated in the presence of the secondary antibody; $(b, e, h, k)$ sections were also from the $65-4$ line; $(c, f, i, l)$ sections were from animals of the 314-4 line (mPl-hGH-hGH $3^{\prime}$ ). The arrow in 1 shows the punctile hGH staining seen in the acrosome of stage 3-4 tubules. Additional negative controls included both the primary and secondary antibody on testes from nontransgenic animals. 


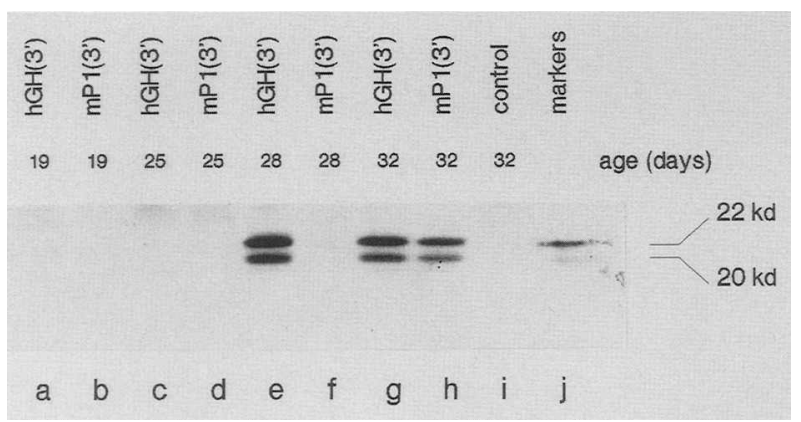

Figure 5. Prepubertal Western blot analysis. Total SDS-soluble protein extracts from testes were prepared from prepubertal animals of the 314-4 line (lanes $a, c, e, g$ ) and 65-4 line (lanes $b, d, f, h$ ). Equivalent amounts of protein from each prepubertal time point $\{60 \mu\}$, day $19 ; 40 \mu \mathrm{l}$, day $25 ; 30 \mu\}$, day 28 ; and $20 \mu \mathrm{l}$, day 32 ) were precipitated with $20 \%$ TCA, separated by SDS-PAGE, electroblotted, and treated with rabbit anti-hGH antibody and a peroxidase-conjugated goat anti-rabbit IgG secondary antibody, as described in Methods. (Lane j) Media harvested from tissue-culture cells (BHK cells) transfected with a metallothionein-hGH fusion and precipitated with $20 \%$ TCA. (Right) Known molecular weights of the two forms of the mature secreted growth hormone (DeNoto et al. 1981).

$\sim 22 \mathrm{kD}$ was observed in animals carrying either transgene. A protein of the same size was found in the culture media from baby hamster kidney (BHK) cells that had been transfected with a metallothionin-hGH gene (lane i) and corresponds to the mature form of hGH generated by cleavage of its amino-terminal signal peptide (DeNoto et al. 1981). Therefore, regardless of the subcellular localization of $\mathrm{hGH}$, its signal peptide was properly cleaved. A second protein of $\sim 20 \mathrm{kD}$ was also observed and probably corresponds to a variant of the mature protein generated by alternative splicing that eliminates the coding sequence for the first 15 amino acids of the third exon of the hGH gene (Lewis et al. 1978; DeNoto et al. 1981). The ratio of the two proteins is different than that observed in BHK cells transfected with a metallothionin-hGH gene (cf. lanes $h$ and $j$ ) and in the pituitary (Lewis et al. 1978; DeNoto et al. 1981; Cooke et al. 1988 !. We have not determined whether the altered ratio of the two proteins in the testis is due to differences in the frequency of the alternative splicing event or to differences in the stability of the two proteins.

\section{Differential stability of transgene mRNAs}

The immunocytochemical analyses described above revealed that if hGH was synthesized in elongating spermatids, it was intracellular but not acrosomal, whereas if it was synthesized in round spermatids, it was localized in the acrosome. In light of this, we wondered why mPl-hGH-hGH $3^{\prime}$ mRNA was not translated in both round and in elongating spermatids, resulting in both acrosomal and nonacrosomal localization of $\mathrm{hGH}$. One explanation could be that mP1-hGH-hGH $3^{\prime}$ mRNA was only present in round spermatids. To determine whether the mPl-hGH-mPl $3^{\prime}$ and mPl-hGH-hGH $3^{\prime}$ mRNAs were present in both early-and late-stage spermatids, we performed in situ hybridization experiments with $\mathrm{mPl}$ and hGH-specific probes.

Hybridization of testis serial sections from a mPlhGH-mP1 $3^{\prime}$ animal with ${ }^{35}$ S-labeled, mPl-specific (Fig. 6a,b) and hGH-specific (Fig. 6c,d) antisense RNA probes shows that the transgenic mRNA was present in the same staged tubules as was the endogenous mPl mRNA, suggesting that the stabilities of the endogenous and transgenic mRNA are similar. However, comparison of serial sections from a mPl-hGH-hGH 3' animal hybridized with the $\mathrm{mPl}$-specific (Fig. 6e,f) and hGH-specific (Fig. $6 \mathrm{~g}, \mathrm{~h}$ ) antisense RNA probes shows that the overall pattern of hybridization with the two probes was different. Whereas those tubules that contained earlystage spermatids show the same hybridization signal with both probes, tubules with later stage spermatids only hybridized with the $\mathrm{mP} 1$ riboprobe, suggesting that the endogenous mP1 mRNA and the mP1-hGH-hGH 3' transgenic mRNA have different stabilities.

\section{Discussion}

\section{Translational control}

We have shown that chimeric transgenes containing the promoter and transcriptional regulatory elements of the $\mathrm{mPl}$ gene, the hGH structural gene, and the $\mathrm{mPl} 3^{\prime}$ UTR are under the same transcriptional and translational control as the endogenous $\mathrm{mP1}$ gene. These data and others (Peschon et al. 1989) demonstrate that all of the cis-acting sequence elements required for spermatidspecific transcription of $\mathrm{mPl}$ lie between $-465 \mathrm{bp}$ and the start of transcription. The $\mathrm{mP} 13^{\prime}$ UTR is critical for both delaying translation until the late stages of spermiogenesis and for mRNA stability. The importance of the mP1 3' UTR in translational control was predicted based on sequence conservation among the $3^{\prime}$ UTRs of the mouse, human, and bovine protamine 1 genes (Krawetz et al. 1987; Lee et al. 1987a,b; Peschon et al. 1987). All three genes share at least $75 \%$ similarity in their $3^{\prime}$ UTRs, with the most conserved regions mapping near the poly $(\mathrm{A})$ site. In fact, the mouse and human genes are more similar in their $3^{\prime}$ UTRs $(89 \%)$ than they are in their protein-coding sequence $(69 \%)$. Sequences in $3^{\prime}$ UTRs have also been shown to be involved in iron-dependent regulation of transferrin receptor mRNA /Casey et al. 1988), plastid mRNA regulation (Gruissem et al. 1988 , and t-PA translational control in mouse oocytes [Strickland et al. 1988).

In amphibians and in marine invertebrates, translational regulation is a common regulatory mechanism during oogenesis and early embryogenesis (Davidson 1986; Richter 1987; Rosenthal and Wilt 1987). In addition to there being a general overall inhibition of translation in unfertilized versus fertilized eggs, there are examples of both selective inhibition (Ford et al. 1977) and selective activation (Rosenthal et al. 1980) of translation. In mouse oogenesis, the tissue plasminogen activator gene (Huarte et al. 1987; Strickland et al, 1988) is 


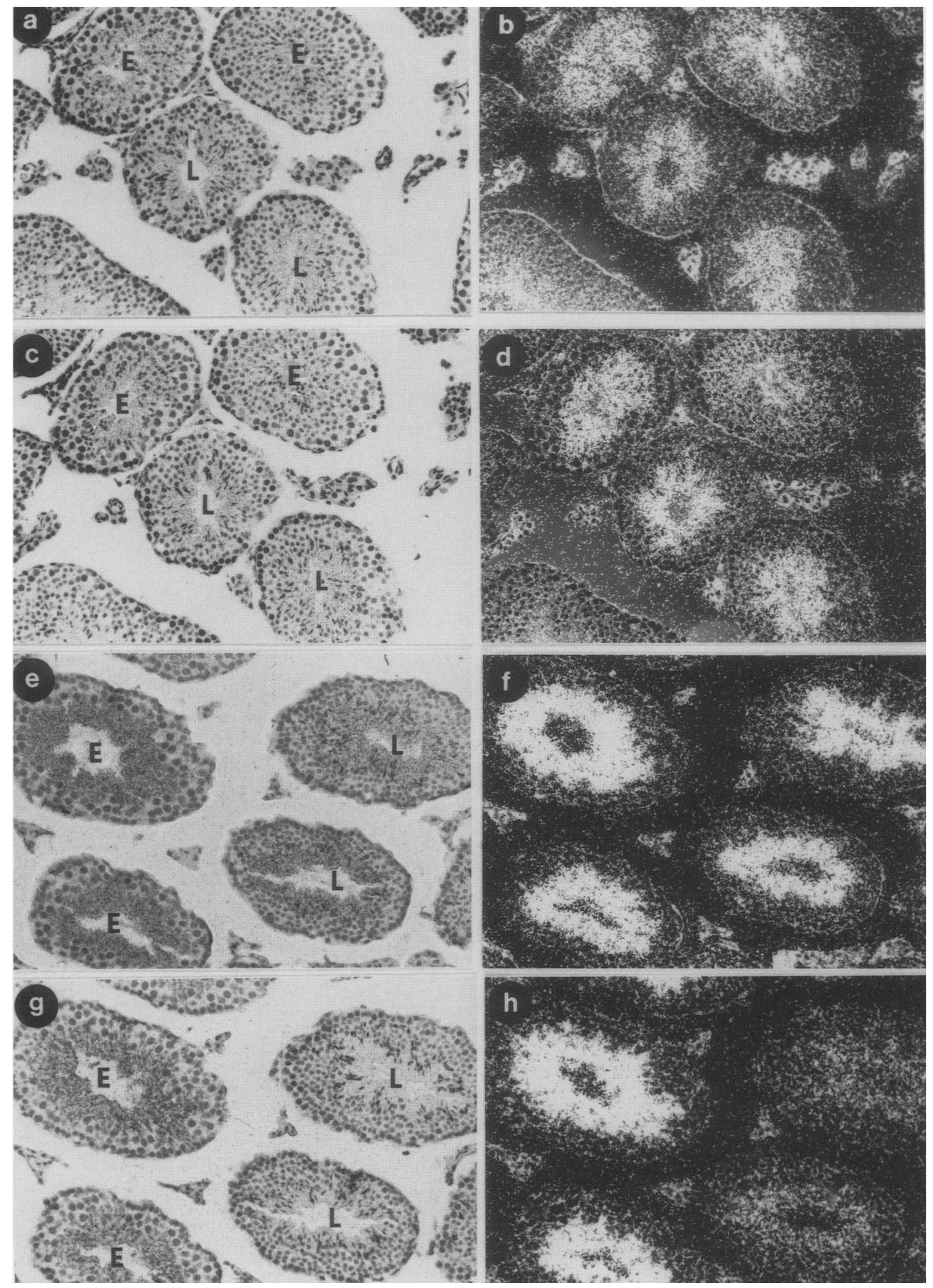

Figure 6. In situ hybridization. Serial sections of testes from either the $65-4$ line [mPl-hGH-mP1 $\left.3^{\prime}(a-d)\right]$ or the $314-4$ line [mPlhGH-hGH $\left.3^{\prime} ;(e-h)\right]$ were hybridized with a ${ }^{35}$ S-labeled $\mathrm{mPl}$-specific antisense probe $(a, b, e, f)$ or an hGH-specific antisense probe $(c, d, g, h)$, as described in Methods. Negative controls included hybridization with a mP1-specific sense probe or an hGH-specific sense probe (data not shown). (E) Early-stage spermatids; (L) late-stage spermatids. (Left) Bright-field microscopy; (right) dark-field microscopy. 
transcribed in primary oocytes but is not translated until their maturation. During recent years, the importance of translational control during spermatogenesis has also become apparent. Specific genes that are regulated posttranscriptionally include the mouse PGK-2 gene /Gold et al. 1983), the trout protamine genes (Iatrou and Dixon 1978), the rat TP1 gene (Heidaran et al. 1988), and the Drosophila mst(3)gl-9 gene (Kuhn et al. 1988). In oogenesis and early embryogenesis, the two mechanisms that are thought to play a role in inhibiting translation are limitations of specific translation factors (Richter and Smith 1981; Collin and Hille 1986) and masking of mRNAs by proteins (Rosenthal et al. 1980). In one special case-the histone mRNAs of sea urchins - translation is inhibited by sequestering the mRNA in the female pronucleus until nuclear membrane breakdown during the first mitotic division (Goustin 1981; Wells et al. 1981; Angerer et al. 1984). The association of mP1 mRNA with mRNPs in early spermatids (Kleene et al. 1984), where it is not translated, and with polysomes in elongating spermatids, where it is translated, suggests that masking of mPl mRNA inhibits its translation in round spermatids. Because the mP1 mRNA is present at $\sim 10,000$ copies per cell $\mid$ R. Palmiter and D. Wolgemuth, unpubl.), it is likely that factors that bind to MPl mRNA are also abundant. We are currently attempting to purify such factors.

The mRNA for $\mathrm{mPl}$ is initially found in round spermatids as a 560-nucleotide transcript and later in elongating spermatids as a heterogeneous size class of molecules down to as small as 400 nucleotides (Fig. 3 , lanes 1-o; Kleene et al. 1984). This decrease in mRNA size is due to a shortening of the poly $|\mathrm{A}|$ tail and occurs at the same time as translation of $\mathrm{mP} 1$ commences. It has yet to be resolved if deadenylation is a prerequisite for, or a consequence of, translation. Deadenylation also seems to be associated with translation of Xenopus oocyte histone mRNAs (Ruderman et al. 1979). In other systems it is usually polyadenylation that is correlated with translation (Wilt 1977; Rosenthal et al. 1983; Rosenthal and Ruderman 1987).

\section{Message stability}

Although we detected mPl-hGH-mPl 3' mRNA by in situ hybridization in both early- and late-stage spermatids, mPl-hGH-hGH $3^{\prime}$ mRNA was clearly more abundant in early spermatids than in late-stage spermatids. Because both genes are first transcribed at about stage 3-4 of spermiogenesis and overall transcription ceases at about stage 9 (Monesi 1964; Kierszenbaum and Tres 1975), transcriptional differences are not likely to be involved. However, the half-lives of the two mRNAs could be different. Such a difference could be due to two, not mutually exclusive, possibilities. First, sequences present in hGH 3' UTR could be directly responsible for a change in half-life. In both prokaryotes and eukaryotes, 3' UTRs have been shown to affect mRNA stability (Shaw and Kamen 1986; Brawerman 1987). Second, premature translation of the mP1-hGH-hGH $3^{\prime}$ mRNA relative to the mP1-hGH-mP1 $3^{\prime}$ mRNA could indirectly lead to a shorter half-life. Linkage between mRNA stability and ongoing protein synthesis is a common occurrence and may reflect the association of RNases with the translational apparatus (Graves et al. 1987, Yen et al. 1988).

\section{Protein sorting}

Most cells have either a constitutive secretory pathway, in which proteins are rapidly exported from the cell following their synthesis, or a regulated secretory pathway, in which proteins are stored in vesicles until their release following the appropriate signal (Tartakoff and Vassalli 1978; Burgess and Kelly 1987). Proteins in both pathways are synthesized on the rough endoplasmic reticulum (RER), pass through the cis-cisternae of the Golgi complex together, and are sorted in the trans-cisternae (Palade 1975; Orci et al. 1987; Tooze et al. 1987). hGH is normally expressed in the pituitary and is a member of the regulated class of secretory proteins (Burgess and Kelly 1987). The acrosome is a regulated secretory vesicle in that its contents are stored until their release following induction of the acrosome reaction during fertilization (Wassarman 1987). Translation of mP1-hGH-hGH $3^{\prime}$ mRNA in early spermatids resulted in localization of hGH in the acrosomal compartment suggesting that the hGH protein is recognized as an acrosomal protein when synthesized in early spermatids. In some regulated secretory systems, for example, in lysosomal vesicles, proteins are recognized and sorted as a result of covalent modification (von Figura and Weber 1978; Farquhar 1985). The sorting signals for hGH are currently unknown but do not involve protein modification (Guan and Rose 1984; Moore and Kelly 1986). The localization of hGH in the acrosome suggests that the protein-sorting machinery used in spermatids to construct the acrosome is functionally equivalent to that used in pituitary cells.

\section{Acrosome development}

Acrosome development begins early in spermiogenesis and consists of four basic steps: the Golgi phase, stages $1-3$; the cap phase, stages $4-7$; the acrosome phase, stages $8-11$; and the maturation phase, stages 12-16 (Leblond and Clermont 1952; Oakberg 1956; Dooher and Bennett 1973). In mP1-hGH-hGH 3' animals, hGH first appeared in the developing acrosome of round spermatids at about stages $3-4$, whereas in $\mathrm{mPl}-\mathrm{hGH}-\mathrm{mPl}$ $3^{\prime}$ animals, hGH protein first appeared in elongating spermatids at about stage 12 and was not acrosomal. Because the signal peptide was removed, we presume that the mRNA was translated on RER and is sequestered in some, as yet undetermined, organelle. Nonetheless, the failure of $\mathrm{hGH}$, synthesized during stages $12-15$, to enter the acrosome suggests that the system targeting $\mathrm{hGH}$ to the acrosome in round spermatids is no longer functional in elongating spermatids, implying that the sorting of normal acrosomal proteins is completed before or soon after the beginning of the maturation phase. Electron microscopy has shown that the Golgi apparatus 
moves caudally during the later stages of spermiogenesis and that an extensive network of various forms of RER extends throughout the cytoplasm (Susi et al. 1971; Clermont and Rambourg 1978). The intracellular localization of $\mathrm{hGH}$ thus serves as a molecular marker for the cessation of acrosomal protein synthesis. Of interest is the signal that marks the completion of acrosomal assembly and the mechanism that dissociates the Golgi from the acrosome.

In cells that have both a regulated and constitutive secretory pathway, blockage of the regulated pathway results in rerouting of the proteins destined for the regulated pathway into the constitutive pathway, resulting in rapid secretion (Neufeld et al. 1975; Moore et al. 1983|. The fact that hGH does not appear to be secreted in elongating spermatids suggests that they do not have a constitutive secretory pathway. Alternatively, either another regulated pathway may be established late in spermiogenesis or remnants of the sorting signals for the acrosomal pathway, although disconnected from the acrosome, may still be present.

\section{Methods \\ DNA and RNA analysis}

DNA manipulations were performed using standard procedures. RNA used for Northern blot analysis was extracted by homogenization in guanidinium isothiocyanate, followed by precipitation with lithium chloride, as described by Cathala et al. (1983). RNA samples were electrophoresed in $1.5 \%$ agaroseformaldehyde gels, transferred to nitrocellulose paper, and hybridized with radioactive DNA probes prepared by nick translation or random oligonucleotide-primed synthesis (Feinberg and Volgelstein 1983). Single-stranded ${ }^{35}$ S-containing sense and antisense riboprobes were made in vitro with linear templates and either SP6 or T7 RNA polymerase (Melton et al. 1984). The $\mathrm{mPl}$ template was made by cloning a 250 -bp restriction fragment containing a portion of $\mathrm{mPl}$ exon 1 , the intron, and a portion of $\mathrm{mPl}$ exon 2 into pGEM-2. The hGH template was constructed by cloning a 170 -bp restriction fragment containing hGH exon 5 into pGEM-2.

\section{Microinjection}

The pronuclei of fertilized eggs derived from $(\mathrm{C} 57 \mathrm{BL} / 6 \times \mathrm{SJL}) \mathrm{F}_{1}$ females mated with identical hybrid males were microinjected with $\sim 2 \mathrm{pl}$ of DNA solution, as described by Brinster et al. (1985). Eggs that survived microinjection were implanted into the oviducts of pseudopregnant Swiss foster females. Two lines of transgenic mice were generated and analyzed for each transgene described in Figure 1. Lines 314-4 and 315-6 carry the $\mathrm{mPl}$-hGH-hGH $3^{\prime}$ gene, and lines $65-4$ and 65-9 carry the mP1hGH-mPl 3' gene.

\section{Protein extracts and Western blotting}

Testes were decapsulated and homogenized in $0.8 \mathrm{ml}$ of buffer containing $10 \mathrm{mM}$ HEPES, $50 \mathrm{~mm} \mathrm{NaCl}, 10 \mathrm{~mm}$ EDTA, and 0.2 $\mathrm{mM}$ PMSF. The proteins were solubilized in $10 \%$ SDS on ice for $15 \mathrm{~min}$, sonicated until they were no longer viscous, and centrifuged in a microfuge for 5 min. Equivalent amounts of super- natants were precipitated with $20 \%$ TCA, resuspended in Laemmli buffer (Laemmli 1970), boiled, and electrophoresed in SDS-polyacrylamide gels. The proteins were electroblotted onto nitrocellulose (Towbin et al. 1979) for $3 \mathrm{hr}$ at $200 \mathrm{~mA}$ at room temperature. Filters were washed at room temperature for $\mathrm{l}$ hr in $5 \%$ nonfat dry milk and PBS incubated with a $1 / 1000$ dilution of primary antibody overnight at $4^{\circ} \mathrm{C}$, washed in $5 \%$ nonfat dry milk and PBS, incubated with a goat anti-rabbit IgG antibody conjugated to horseradish peroxidase (HRP) (Bio-Rad) for 3 hr at room temperature, and washed again in $5 \%$ nonfat dry milk and PBS. The HRP was detected with a diaminobenzidine substrate (Bio-Rad), using the manufacturer's instructions. Equivalent amounts of protein from all of the prepubertal time points were determined in pilot expermiments by comparing the total amount of protein on Coomassie-stained SDS-PAGE gels.

\section{Immunocytochemistry}

Testes were fixed in Carnoy's reagent, embedded in paraffin, and cut into $5-\mu \mathrm{m}$ sections. Sections were deparaffinized with xylene and rehydrated using standard procedures. Indirect immunocytochemistry was performed using the reagents and suggested protocols of Vectastain $A B C$ and Zymed SABC kits. The primary antibody, rabbit anti-hGH, was obtained from the $\mathrm{Na}$ tional Hormone and Pituitary Program (Baltimore, Maryland), and used at a dilution of 1/25o. Aminoethyl carbazole (Zymed Laboratory, Inc.) was used as the substrate chromogen. Sections were counterstained with hematoxylin. Additional negative controls included the use of both the primary and secondary antibodies on testes isolated from nontransgenic animals.

\section{In situ hybridizations}

Testes were dissected from adult animals, fixed in $4 \%$ paraformaldehyde, embedded in paraffin, and cut into $5-\mu \mathrm{m}$ sections. The paraffin was extracted with xylene and the tissue was rehydrated using standard conditions. The sections were washed twice for $5 \mathrm{~min}$ in $0.1 \mathrm{M} \mathrm{Na}_{2} \mathrm{HPO}_{4} / \mathrm{NaH}_{2} \mathrm{PO}_{4}(\mathrm{pH} 7.5)$, incubated with proteinase $\mathrm{K}$ at $1 \mu \mathrm{g} / \mathrm{ml}$ for $10 \mathrm{~min}$ at $37^{\circ} \mathrm{C}$, washed twice for $2 \mathrm{~min}$ in $\mathrm{H}_{2} \mathrm{O}$, washed once in $0.1 \mathrm{M}$ triethanolamine (TEA) and $150 \mathrm{~mm} \mathrm{NaCl}(\mathrm{pH} 8.0)$ for $2 \mathrm{~min}$, treated with $0.25 \%$ acetic anhydride in $\mathrm{TEA} / \mathrm{NaCl}$ for $10 \mathrm{~min}$, washed twice for $5 \mathrm{~min}$ in $2 \times \mathrm{SSC}$, and hybridized for $6-12 \mathrm{hr}$ at $45^{\circ} \mathrm{C}$ with radioactive probes. Hybridization solution contained $50 \%$ formamide, 0.6 M NaCl, $10 \mathrm{~mm}$ Tris (pH 7.5), $1 \mathrm{~mm}$ EDTA, $1 \times$ Denhardt's solution, $10 \%$ dextran sulfate, $10 \mathrm{mM}$ DTT, and yeast RNA at $50 \mu \mathrm{g} / \mathrm{ml}$. Probes were used at a concentration of $\sim 0.2 \mu \mathrm{g} / \mathrm{ml}$, with an approximate sp. act. of $5 \times 10^{8} \mathrm{cpm} / \mu \mathrm{g}$. Slides were washed twice in $4 \times$ SSC and $5 \mathrm{mM}$ DTT for $15 \mathrm{~min}$, incubated for $30 \mathrm{~min}$ at $37^{\circ} \mathrm{C}$ in $10 \mathrm{~mm}$ Tris, $1 \mathrm{mM}$ EDTA, $500 \mathrm{~mm} \mathrm{NaCl}$, and $25 \mu \mathrm{g} / \mathrm{ml}$ RNase $\mathrm{A}$, washed in $2 \times$ SSC and $2 \mathrm{mM}$ DTT for $60 \mathrm{~min}$ at $22^{\circ} \mathrm{C}$, washed in $0.1 \times \mathrm{SSC}$ and $2 \mathrm{mM}$ DTT for $30 \mathrm{~min}$ at $45^{\circ} \mathrm{C}$, and washed in $0.1 \times$ SSC for $5 \mathrm{~min}$ at $22^{\circ} \mathrm{C}$. Slides were dehydrated with ethanol using standard procedures, dried, dipped in Kodak NTB emulsion, stored at $4^{\circ} \mathrm{C}$, developed after 1-5 days, and counterstained with hematoxylin.

\section{Acknowledgments}

We thank our collegues for critical review of this manuscript. Expert technical assistance was provided by $M$. Avarbock, F. Oram, D. Allen, and G. Froelick. This work was supported, in part, by the Howard Hughes Medical Institute and by grants from the National Institutes of Health (HD-23657 to R.L.B. and HD-09172 to R.D.P.). 


\section{References}

Angerer, L.M., D.V. DeLeon, R.C. Angerer, R.M. Showman, D.E. Wells, and R.A. Raff. 1984. Delayed accumulation of maternal histone mRNA during sea urchin oogenesis. Dev. Biol. 101: 477-484.

Balhorn, R., S. Weston, C. Thomas, and A.J. Wyrobek. 1984. DNA packaging in mouse spermatids. Synthesis of protamine variants and four transition proteins. Exp. Cell. Res. 150: $298-308$.

Bellve, A.R. 1979. The molecular biology of mammalian spermatogenesis. Oxford Rev. Reprod. Biol. 1: 159-261.

Braun, R.E., R.R. Behringer, I.J. Peschon, R.L. Brinster, and R.D. Palmiter. 1989. Genetically haploid spermatids are phenotypically diploid. Nature 337: 373-376.

Brawerman, G. 1987. Determinants of messenger RNA stability. Cell 48: 5-6.

Brinster, R.L., H.Y. Chen, M.E. Trumbauer, M.K. Yagle, and R.D. Palmiter. 1985. Factors affecting the efficiency of introducing foreign DNA into mice by microinjecting eggs. Proc. Natl. Acad. Sci, 82: 4438-4432.

Burgess, T.L. and R.B. Kelly. 1987. Constitutive and regulated secretion of proteins. Annu. Rev. Cell Biol 3: 243-293.

Casey, J.L., M.W. Hentze, D.M. Koeller, S.W. Caughman, T.A. Rouault, R.D. Klausner, and J.B. Harford. 1988. Iron-responsive elements: Regulatory RNA sequences that control mRNA levels and translation. Science 240: 924-928.

Cathala, G., J.F. Savouret, B.L. Mendez, M. Karin, J.A. Martial, and J.D. Baxter. 1983. A method for isolation of intact, translationally active ribonucleic acid. DNA 2: $329-335$.

Clermont, Y. and A. Rambourg. 1978. Evolution of the endoplasmic reticulum during rat spermiogenesis. Am. I. Anat. 151: 191-212.

Colin, A. and M.B. Hille. 1986. Injected mRNA does not increase protein synthesis in unfertilized, fertilized, or ammonia-activated sea urchin eggs. Dev. Biol. 115: 184-192.

Cooke, N.E., J. Ray, M.A. Watson, P.A. Estes, B.A. Kuo, and S.A. Liebhaber. 1988. The human growth hormone gene and the highly homologous growth hormone variant gene display different splicing patterns. /. Clin. Invest. 82: 270-275.

Davidson, E.H. 1986. Gene activity in early development. Academic Press, New York.

DeNoto, F.M., D.D. Moore, and H.M. Goodman. 1981. Human growth hormone DNA sequence and mRNA structure: Possible alternative splicing. Nucleic Acids Res. 9: 3719-3730.

Dooher, G.B. and D. Bennett. 1973. Fine structural observations on the development of the sperm head in the mouse. Am. I. Anat. 136: 339-362.

Farquhar, M.G. 1985. Progress in unraveling pathways of Golgi traffic. Annu. Rev. Cell Biol. 1: 447-488.

Fawcett, D.W. and D.M. Phillips. 1969. The fine structure and development of the neck region of the mammalian spermatozoon. Anat. Rec. 165: 153-184.

Fawcett, D.W., W.A. Anderson, and D.M. Phillips. 1971. Morphogenetic factors influencing the shape of the sperm head. Dev. Biol. 26: 220-251

Feinberg, A.P. and B. Volgelstein. 1983. A technique for radiolabeling DNA restriction endonuclease fragments to high specific activity. Anal. Biochem. 132: 6-12.

Ford, P.J., T. Mathieson, and M. Rosbash. 1977. Very long-lived messenger RNA in ovaries of Xenopus laevis. Dev. Biol. 57: $417-426$.

Gold, B., H. Fujimoto, J.M. Kramer, R.P. Erickson, and N.B. Hecht. 1983. Haploid accumulation and translational control of phosphoglycerate kinase- 2 messenger RNA during mouse spermatogenesis. Dev. Biol, 98: 392-399.
Goustin, A.S. 1981. Two temporal phases for the control of histone gene activity in cleaving sea urchin embryos (S. purpuratus). Dev. Biol. 87; 163-175.

Graves, R.A., N.B. Pandey, N. Chodchoy, and W.F. Marzluff. 1987. Translation is required for regulation of histone mRNA degradation. Cell 48: 615-626.

Gruissem, W., A. Barkan, X. Deng, and D. Stern. 1988. Transcriptional and posttranscriptional control of plastid mRNA levels in higher plants. Trends Genet. 4: 258-263.

Guan, J.L. and J.K. Rose. 1984. Conversion of a secretory protein into a transmembrane protein results in its transport to the Golgi complex but not to the cell surface. Cell 37: $779-$ 787.

Hecht, N.B. 1986. Regulation of gene expression during mammalian spermatogenesis. In Experimental approaches to mammalian embryonic development (ed. J. Rossant and R.A. Pedersen), pp. 151-193. Cambridge University Press, New York.

Hecht, N.B., P.A. Bower, S.H. Waters, P.C. Yelick, and R.J. Distel. 1986. Evidence for haploid expression of mouse testicular genes. Exp. Cell Res. 164: 183-190.

Heidaran, M.A., R.M. Showman, and W.S. Kistler. 1988. A cytochemical study of the transcriptional and translational regulation of nuclear transition protein 1 (TP1), a major chromosomal protein of mammalian spermatids. T. Cell Biol. 106: $1427-1433$.

Huarte, J., D. Belin, A. Vassalli, S. Strickland, and J.D. Vassalli. 1987. Meiotic maturation of mouse oocytes triggers the translation and polyadenylation of dormant tissue-type plasminogen activator mRNA. Genes Dev. 1: 1201-1211.

Iatrou, K. and G.H. Dixon. 1977. Messenger RNA sequences in the developing trout testis. Cell 10: 433-441.

- 1978. Protamine messenger RNA: Its life history during spermatogenesis in rainbow trout. Fed. Proc. 37: 25262533.

Kierszenbaum, A.L. and I.L. Tres. 1975. Structural and transcriptional features of the mouse spermatid genome. $/$. Cell. Biol. 65: 258-270.

Kleene, K.C., R.J. Distel, and N.B. Hecht. 1983. cDNA clones encoding cytoplasmic poly $|\mathrm{A}|+$ RNAs which first appear at detectable levels in haploid phases of spermatogenesis in the mouse. Dev. Biol. 98: 455-464.

-1984. Translational regulation and deadenylation of a protamine mRNA during spermiogenesis in the mouse. Dev. Biol. 105: 71-79.

Krawetz, S.A., W. Connor, and G.H. Dixon. 1987. Cloning of bovine Pl protamine cDNA and the evolution of vertebrate Pl protamines. DNA 6: 47-57.

Kuhn, R., U. Schafer, and M. Schafer. 1988. Cis-acting regions sufficient for spermatocyte-specific transcriptional and spermatid-specific translational control of the Drosophila melanogaster gene mst(3)g1-9. EMBO I. 7: 447-454.

Laemmli, U.K. 1970. Cleavage of structural proteins during the assembly of the head of bacteriophage T4. Nature 227: 680685.

Leblond, C.P. and Y. Clermont. 1952. Spermiogenesis of rat mouse, hamster and guinea pig as revealed by the 'periodic acid-fuschin sulfurous acid' technique. Am. I. Anat, 90; $167-216$

Lee, C.H., S. Hoyer-Fender, and W. Engel. 1987a. The nucleotide sequence of a human protamine $1 \mathrm{cDNA}$. Nucleic Acids Res. 15: 7639.

Lee, C.H., M. Ahmed, W. Hecht, N.B. Hecht, and W. Engel. 1987b. Nucleotide sequence of a bovine protamine cDNA. Biol. Chem. Hoppe-Seyler 368: 131-135.

Lewis, U.J., J.T. Dunn, L.F. Bonewald, B.K. Seavey, and W.P. 
Vanderlaan. 1978. A naturally occuring structural variant of human growth hormone. I. Biol. Chem. 253: 2679-2687.

Mason, K.E. and S.L. Shaver. 1952, Some functions of the caput epididymis. Ann. N.Y. Acad. Sci. 55: 585-593.

Melton, D.A., P.A. Krieg, M.R. Rebagliati, T. Maniatis, K. Zinn, and M.R. Green. 1984. Efficient in vitro synthesis of biologically active RNA and RNA hybridization probes from plasmids containing a bacteriophage SP6 promoter. Nucleic Acids Res. 12: 7035-7056.

Monesi, V. 1964. Ribonucleic acid synthesis during mitosis and meiosis in the mouse testis. J. Cell Biol. 22: 521-532.

Moore, H.P.H. and R.B. Kelly. 1986. Re-routing of a secretory protein by fusion with human growth hormone sequences. Nature 321: 443-446.

Moore, H.P., B. Gumbiner, and R.B. Kelly. 1983. Chloroquine diverts ACTH from a regulated to a constitutive secretory pathway in AtT-20 cells. Nature 302: 434-436.

Nebel, B.R., A.P. Amarose, and E.M. Hackett. 1961. Calendar of gametogenic development in the prepuberal male mouse. Science 134: 832-833.

Neufeld, E.F., T.W. Lim, and L.J. Shapiro. 1975. Inherited disorders of lysozomal metabolism. Annu. Rev. Biochem. 44: $357-376$.

O'Brien D.A. and A.R. Bellve. 1980. Protein constituents of the mouse spermatozoon. Dev. Biol. 75: 405-418.

Oakberg, E.F. 1956. A description of spermiogenesis in the mouse and its use in analysis of the cycle of the seminiferous epithelium and germ cell renewel. Am. I. Anat. 99: $391-413$

Olivieri, G. and A. Olivieri. 1965. Autoradiographic study of nucleic acid synthesis during spermatogenesis in Drosophila melanogaster. Mutation Res. 2: 366-380.

Orci, L., M. Ravazzola, M. Amherdt, A. Perrelet, S.K. Powell, D.L. Quinn, and H.P.H. Moore. 1987. The trans-most cisternae of the Golgi complex: A compartment for sorting of secretory and plasma membrane proteins. Cell 51: 10391051.

Palade, G. 1975. Intracellular aspects of the process of protein synthesis. Science 189: 347-358.

Peschon, J.J., R.R. Behringer, R.L. Brinster, and R.D. Palmiter. 1987. Spermatid specific expression of protamine 1 in transgenic mice. Proc. Natl. Acad. Sci. 84: 5316-5319.

Peschon, J.J., R.R. Behringer, R.D. Palmiter, and R.L. Brinster. 1989. Expression of mouse protamine 1 genes in transgenic mice. In 1989 testis workshop. New York Academy of Sciences (in press).

Richter, J.D. 1987. Molecular mechanisms of translational control during the early development of Xenopus laevis. In Translational regulation of gene expression (ed. J. Ilan), pp. 111-153. Plenum Press, New York.

Richter, J.D. and L.D. Smith. 1981. Differential capacity for translational and lack of competion between mRNAs that segregate to free and membrane-bound polysomes. Cell 27: 183-191.

Rosenthal, E.T. and J.V. Ruderman. 1987. Widespread changes in the translation and adenylation of matemal messenger RNAs following fertilization of Spisula oocytes. Dev. Biol. 121: $237-246$

Rosenthal, E. and F. Wilt. 1987. Selective messenger RNA translation in marine invertebrate oocytes, eggs, and zygotes. In Translational regulation of gene expression (ed. J. Ilan), pp. 87-110. Plenum Press, New York.

Rosenthal, E.T., T. Hunt, and J.V. Ruderman. 1980 Selective translation of mRNA controls the pattern of protein synthesis during early development of the surf clam, Spisula solidissima. Cell 20: 487-494.
Rosenthal, E.T., T.R. Tansey, and J.V. Ruderman. 1983. Sequence-specific adenylations and deadenylations accompany changes in the translation of maternal messenger RNA after fertilization of Spisula oocytes. I. Mol. Biol. 166: 309327.

Ruderman, J.V., H.R. Woodland, and E.A. Sturges. 1979. Modulations of histone messenger RNA during the early development of Xenopus laevis. Dev. Biol. 71: 71-82.

Shaw, G. and R. Kamen. 1986. A conserved AU sequence from the $3^{\prime}$ untranslated region of GM-CSF mRNA mediates selective mRNA degradation. Cell 46: 659-667.

Strickland, S., J. Huarte, D. Belin, A. Vassalli, R.J. Rickles, and J.D. Vassalli. 1988 Antisense RNA directed against the $3^{\prime}$ noncoding region prevents dormant mRNA activation in mouse oocytes. Science 241: 680-684.

Susi, F.R., C.P. Leblond, and Y. Clermont. 1971 Changes in the Golgi apparatus during spermiogenesis in the rat. Am. J. Anat. 130: 251-268.

Tartakoff, A. and P. Vassalli. 1978. Comparitive studies of intracellular transport of secretory proteins. I. Cell Biol. 79: 694-707.

Tooze, J., S.A. Tooze, and S.D. Fuller. 1987. Sorting of progeny Coronavirus from condensed secretory proteins at the exit from the trans-Golgi network of AtT20 cells. $/$. Cell. Biol. 105: $1215-1226$

Towbin, H., T. Staehelin, and J. Gordon. 1979. Electrophoretic transfer of proteins from polyacrylamide gels into nitrocellulose sheets. Procedure and some applications. Proc. Natl. Acad. Sci. 76: 4350-4354.

von Figura, K. and E. Weber. 1978. An alternative hypothesis of cellular transport of lysosomal enzymes in fibroblasts. Biochem. I. 176: 943-950.

Wassarman, P.M. 1987. The biology and chemistry of fertilization. Science 30: 553-560.

Wells, D.E., R.M. Showman, W.H. Klein, and R.A. Raff. 1981. Delayed recruitment of maternal histone $\mathrm{H} 3 \mathrm{mRNA}$ in sea urchin embryos. Nature 292: 477-478.

Wilt, F.H. 1977. The dynamics of maternal poly(A)-containing mRNA in fertilized sea urchin eggs. Cell 11: 673-681.

Yen, T.J., P.S. Machlin, and D.W. Cleveland. 1988. Autoregulated instability of Beta-tubulin mRNAs by recognition of the nascent amino terminus of Beta-tubulin. Nature 334: 580-585. 


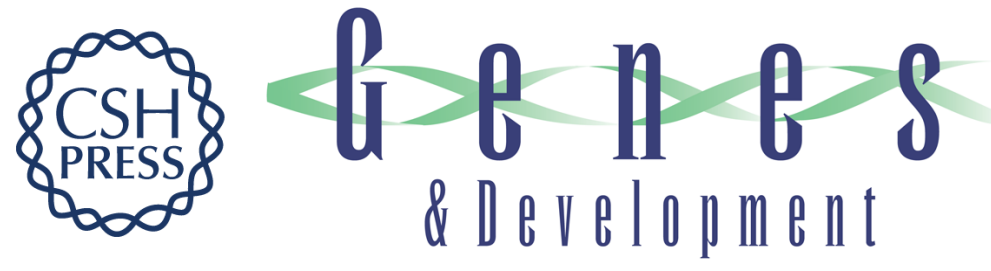

\section{Protamine 3'-untranslated sequences regulate temporal translational control and subcellular localization of growth hormone in spermatids of transgenic mice.}

R E Braun, J J Peschon, R R Behringer, et al.

Genes Dev. 1989, 3:

Access the most recent version at doi:10.1101/gad.3.6.793

References This article cites 67 articles, 13 of which can be accessed free at: http://genesdev.cshlp.org/content/3/6/793.full.html\#ref-list-1

License

Email Alerting Service

Receive free email alerts when new articles cite this article - sign up in the box at the top right corner of the article or click here.

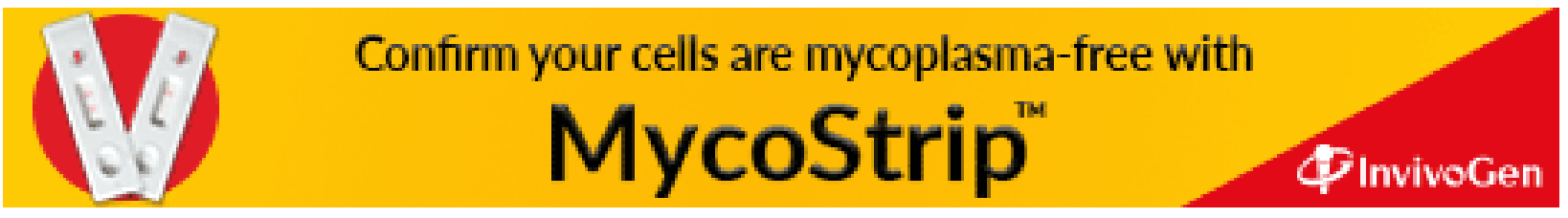

